Bull. Mater. Sci., Vol. 17, No. 6, November 1994, pp. 747-770. (C) Printed in India.

\title{
The hardness-flow stress correlation in metallic materials
}

\author{
G SUNDARARAJAN and $Y$ TIRUPATAIAH \\ Defence Metallurgical Research Laboratory, P.O. Kanchanbagh, Hyderabad 500 258, India
}

\begin{abstract}
Hardness is a measure of the resistance of a material to indentation and a wide variety of indentation tests have been devised to measure the hardness of materials. In the case of hardness tests which utilize spherical balls as the indentor, it is also possible to derive flow stress-strain relationships from hardness tests carried out either over a range of loads (static test) or over a range of impact velocities (dynamic test). This paper first describes the experimental procedure for obtaining stress-strain curves from hardness tests. In addition, the paper also analyzes in detail, the indentation test conditions under which the conversion of the hardness-average strain data to flow stress-strain data is simple and straightforward in the sense that the constraint factor which is the correlating parameter for the above conversion is not only independent of strain but also easily computable on the basis of known mechanical property data of the test material.
\end{abstract}

Keywords. Hardness-flow stress; static hardness; dynamic hardness; impact velocity; constraint facto Meyer hardness.

\section{Introduction}

Indentation tests carried out to measure the hardness of materials are usually referred to as hardness tests. Such tests usually involve the indentation of the test material with an indenter at a constant load $(P)$ and the subsequent measurement of the dimensions of the indent that is formed on the test material. The hardness $(H)$ is then obtained as,

$$
H=P / A \text {, }
$$

where $A$ is the area of the indent formed on the test material. It is more appropriate and scientific to define $A$ as the projected area of the indent rather than surface area, eventhough some of the well-known hardness tests usually define hardness in terms of the surface area of the indent. The hardness values obtained using projected area are usually distinguished from those obtained using surface area of the indent, by specifying the former as the projected area hardness (PAH).

The hardness tests can be classified either on the basis of the indentation test conditions (temperature and strain rate) or on the basis of the depth of indentation, as illustrated in figure 1 . The well known conventional hardness tests, called static hardness in figure 1a, are carried out at around room temperature and the strain rate at which the plastic deformation of the test material occurs during indentation, lies in the range $10^{-3}$ to $10^{-1} \mathrm{~s}^{-1}$. In contrast, dynamic hardness, involves strain rates in the range $10^{3}$ to $10^{5} \mathrm{~s}^{-1}$. The hot hardness involves testing the material at temperatures in the range 0.4 to $0.8 T_{\mathrm{m}}\left(T_{\mathrm{m}}\right.$ is the melting point of the test material) and at static strain rates $\left(10^{-3}\right.$ to $\left.10^{-1} \mathrm{~s}^{-1}\right)$. The creep hardness (or impression creep) 


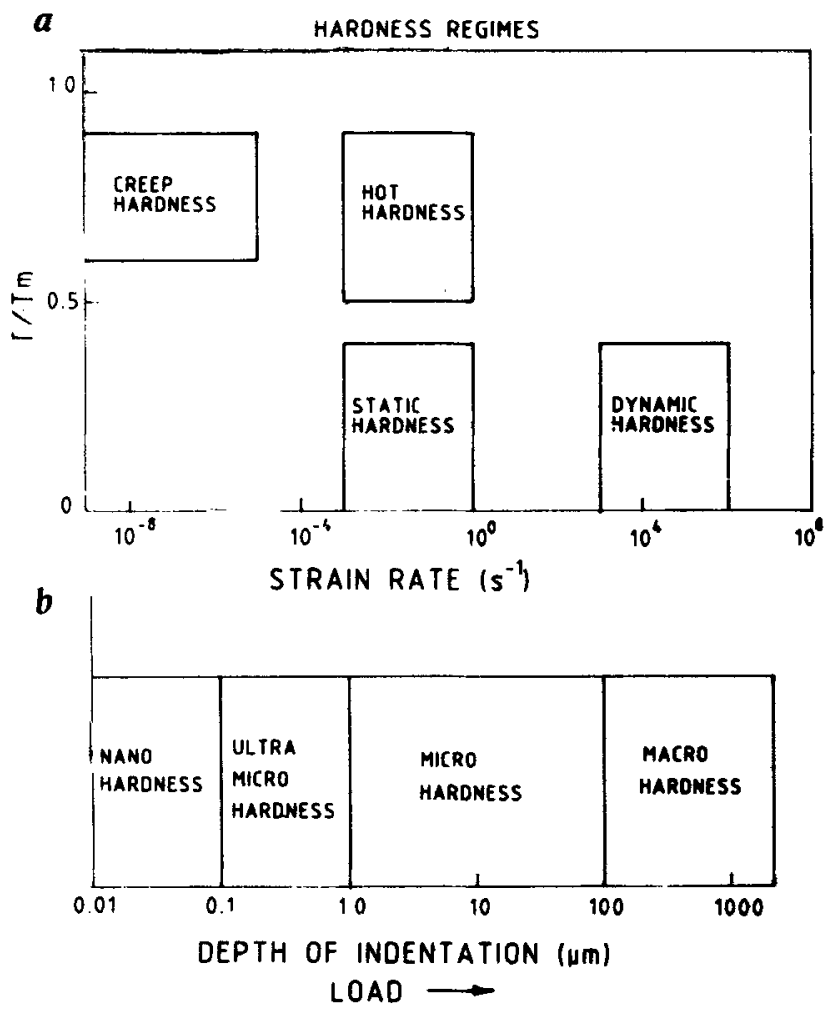

Figure 1. The classification of hardness tests on the basis of indentation test conditions (a) and depth of indentation (b).

is time dependent and is usually carried out for long times at temperatures above $0.4 T_{\mathrm{m}}$ and at strain rates below $10^{5} \mathrm{~s}^{-1}$ or so. All the hardness tests described above generally use indentation loads well in excess of $100 \mathrm{~g}$ and are classified as macrohardness tests. In such tests, the depth of indentation lies in the range 100 to a few thousand micrometers, as indicated in figure $1 \mathrm{~b}$. The microhardness tessts wherein the indentation load lies in the range 1 to $100 \mathrm{~g}$, are characterized by depth of indentation in the range 1 to $100 \mu \mathrm{ms}$. The nanohardness tests, wherein the test material is indented only up to a depth of $100 \mathrm{~nm}$ or less (figure 1b), represents the extreme case. Finally, the ultra microhardness tests, span the range in between that of nano and microhardness tests.

Apart from determining the hardness, the hardness tests can actually be used to obtain the plastic flow stress $(\sigma)$-plastic strain $(\varepsilon)$ behaviour of materials (Tabor 1951; O'Neill 1967; Sundararajan and Shewmon 1983). The conditions under which the determination of the $\sigma-\varepsilon$ curve using a hardness test becomes attractive, are listed below.

(i) The hardness test is a simple test and further requires samples having simple shapes. Thus, either when the sample size is limited because of the process technology involved or when the number of materials to be tested is large, the use of hardness test to obtain the $\sigma-\varepsilon$ curve proves very effective. 
(ii) A number of engineering components are currently being coated with a variety of materials in order to improve their durability in service. The hardness test provides the only means to estimate the $\sigma-\varepsilon$ behaviour of the coatings since by adjusting the indentation load, it can be ensured that only the coating is sampled during the hardness test. In this respect, the nano and ultra microhardness tests have proved extremely useful.

(iii) In the case of very brittle materials like ceramics, hardness test can be utilized to generate $\sigma-\varepsilon$ curves since the presence of a substantial hydrostatic compressive stress during indentation postpones fracture to larger strains.

The conversion of hardness to flow stress, at a given constant strain, requires prior knowledge about the constraint factor $(C) . C$ is defined as,

$$
C=H(\varepsilon) / \sigma(\varepsilon),
$$

where $H$ and $\sigma$ are the hardness and flow stress at the same strain. A primary requirement for $C$ is that it should be independent of strain. The present paper is concerned with providing a brief overview of the test and validation procedures involved in the determination of hardness-strain curves of metallic materials and their subsequent transformation to flow stress-strain curves. In particular, the test conditions under which the hardness test data can be effectively utilized for estimating the flow stress, is also highlighted.

\section{Hardness-strain relationship}

\subsection{Introduction}

During the indentation test, a plastic zone is formed underneath the indenter as illustrated in figure $2 a$. Within the plastic zone, there exists a plastic strain gradient (see figure $2 b$ ). The plastic strain which is maximum at the indenter-sample interface decreases continuously with increasing depth from the sample-indenter interface and ultimately reaches zero at the elastic-plastic boundary (figure $2 \mathrm{~b}$ ). Thus, an average or representative strain $\left(\varepsilon_{\mathrm{av}}\right)$ can be assigned to the plastic zone. In the case of spherical indentors, the magnitude of $\varepsilon_{\mathrm{av}}$ is determined by the dimensions of the indent formed while for conical and pyramidal indentors, the included angle of the indentor determines $\varepsilon_{\mathrm{av}}$ (Johnson 1985). Therefore, it follows that while the Vickers indentor induces a constant average strain of $8 \%\left(\varepsilon_{\mathrm{av}} \simeq 8 \%\right)$ irrespective of the load applied, in the case of spherical indentor the magnitude of $\varepsilon_{\mathrm{av}}$ depends on indent dimensions and hence on the applied load.

\subsection{Test procedure}

From the above discussion it is clear that a hardness $(H)-\varepsilon_{\mathrm{av}}$ relationship can be obtained only if spherical indentors are used. Therefore, a conventional Brinell hardness machine is usually utilized to obtain the $H-\varepsilon_{\text {av }}$ relationship. Tungsten carbide (WC) balls of diameter 5 and $10 \mathrm{~mm}$ and test loads in the range 250 to $3000 \mathrm{~kg}$ are usually utilized for conducting the test. Flat specimens, $25 \mathrm{~mm}$ wide, $75 \mathrm{~mm}$ long and $15 \mathrm{~mm}$ thick and polished with emery paper to 600 grit size are used as the test samples for indentation. 


\section{$a$}

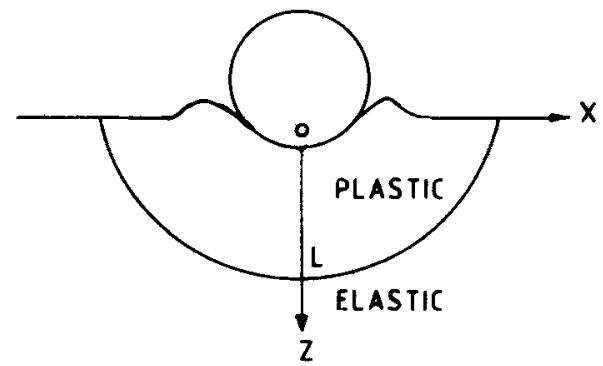

b

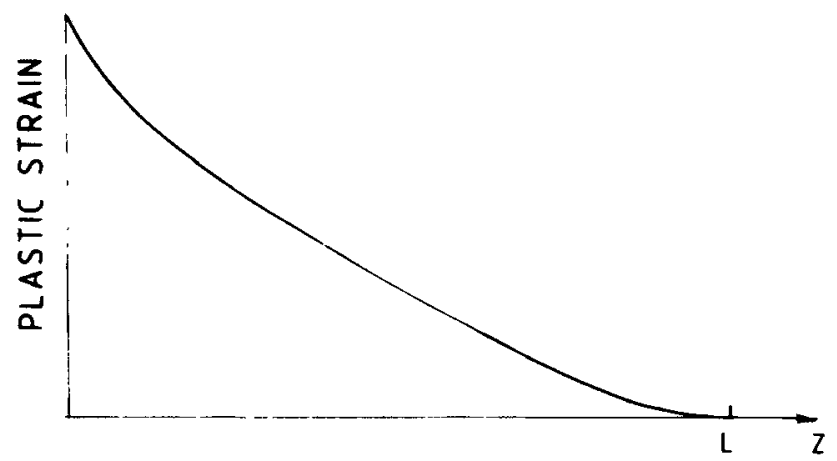

Figure 2. A schematic diagram illustrating the plastic zone formed beneath the indentation (a) and the plastic strain gradient within the plastic zone (b).

The indentation tests are carried out over a range of loads $(L)$ and the diameter of the indent $(W)$ so formed is measured using either an optical microscope or using a surface profile measuring equipment. The hardness $\left(H_{\mathrm{s}}\right)$ is then obtained as,

$$
H_{\mathrm{s}}=4 L / \pi W^{2}
$$

The most well-known expression for the average strain in the plastic zone $\left(\varepsilon_{\mathrm{av}}\right)$, due to Tabor (1951), is given as,

$$
\varepsilon_{\mathrm{av}}=0.2(W / D)
$$

In (4), $D$ represents the ball diameter.

From (3) and (4) it is obvious that if the indentation tests are carried out over a range of loads, the hardness value can be obtained over a range of average strains. Thus, the $H_{\mathrm{s}}-\varepsilon_{\mathrm{av}}$ relationship can be obtained.

The same concepts described above can be readily extended to the case wherein a $W C$ ball impacts the test sample at considerable velocities $(10$ to $200 \mathrm{~m} / \mathrm{s}$ ) to obtain the dynamic hardness $\left(H_{\mathrm{d}}\right)-\varepsilon_{\mathrm{av}}$ relationship. In the case of dynamic hardness experiments, indents of increasing dimensions (and hence increasing $\varepsilon_{\mathrm{av}}$ ) are easily 
obtained by impacting the sample with $W C$ balls over a range of impact velocities. The value of $H_{\downarrow}$ is obtained as (Tirupataiah and Sundararajan 1991a),

$$
\begin{aligned}
& H_{\mathrm{d}}=0.5 m v^{2}\left(1-e^{2}\right) / V_{\mathrm{c}}, \\
& V_{\mathrm{c}}=\pi d^{2} r(1-(d / 3 r)), \\
& d=r\left[1-\left(1-\left(W^{2} / 4 r^{2}\right)\right)^{1 / 2}\right] .
\end{aligned}
$$

In (5) to (7), $m$ is the mass of ball, $v$ the impact velocity, $e$ the coefficient of restitution (see Tirupataiah et al (1990) for more details), $V_{c}$ the indent volume, $r$ the ball radius, $W$ the indent diameter and $d$ the maximum indent depth during impact. The average strain $\left(\varepsilon_{\mathrm{av}}\right)$ is determined by (4) given earlier even under dynamic impact conditions. Thus, using (4) to (7), $H_{\mathrm{d}}-\varepsilon_{\mathrm{av}}$ relationship can be obtained for a given test material.

The major difference between the dynamic and static hardness tests (i.e. $H_{\mathrm{d}}$ and $H_{s}$ ) lies in the fact that the strain rate at which the plastic deformation occurs in the plastic zone (in the sample) during the two tests are vastly different. While the strain rates are around $10^{-3}$ to $10^{-2} \mathrm{~s}^{-1}$ in the static tests, the corresponding strain rates in the dynamic tests lie in the range $10^{3}$ to $10^{4} \mathrm{~s}^{-1}$ (Tirupataiah et al 1991a). The strain rates are thus 6 orders of magnitude higher during dynamic indentation as compared to static indentation.

\subsection{Results}

The variation of dynamic and static hardness with average strain, as obtained using the techniques described in $\S 2 \cdot 2$, are illustrated for $\mathrm{Cu}$ and $\mathrm{Cu}$ alloys, iron and steel and $\mathrm{Ni}$ and $\mathrm{Ni}$ base alloys in figures 3,4 and 5 respectively. In all these figures, the filled circles represent the dynamic data while the unfilled circles correspond to the static data. For all the materials illustrated in figures 3-5 (i.e. $\mathrm{Cu}, \mathrm{Cu}-\mathrm{Zn}, \mathrm{Cu}-\mathrm{Al}, \mathrm{Fe}, \mathrm{Hv} 260$ steel, Ni, Ni-20 Cr and MA 754 alloy) the dynamic hardness $-\varepsilon_{\mathrm{av}}$ curve clearly lies above the static hardness $-\varepsilon_{\mathrm{av}}$ curve pointing to the fact that the hardness of all these materials exhibit a positive strain rate sensitivity with regard to strength.

The ratio of dynamic to static hardness (i.e. $H_{\mathrm{d}} / H_{\mathrm{s}}$ ) at a constant strain of $7 \%$ is presented in figure $6 \mathrm{a}$ for a number of metallic materials. In the case of pure metals like $\mathrm{Al}$ and $\mathrm{Fe}, H_{\mathrm{J}}$ is more than twice $H_{\mathrm{s}}$ pointing to extreme strain rate sensitivity. In the case of the other materials, as can be noted from figure $6 \mathrm{a}, H_{\mathrm{d}}$ is about 20 to $40 \%$ higher than $H_{s}$.

The dynamic and static hardness $-\varepsilon_{\mathrm{av}}$ curves are usually fitted to equations of the following form

$$
\begin{aligned}
& H_{\mathrm{s}}=H_{\mathrm{os}} \cdot \varepsilon_{\mathrm{av}}^{n_{\mathrm{d}}}, \\
& H_{\mathrm{d}}=H_{\mathrm{od}} \cdot \varepsilon_{\mathrm{av}}^{n_{d}} .
\end{aligned}
$$

In (8) and (9), $H_{\text {os }}$ and $H_{\text {od }}$ represent the static and dynamic hardness coefficients and $n_{\mathrm{d}}$ and $n_{\mathrm{M}}$ correspond to the dynamic and static strain hardening exponents respectively. The ratio $H_{\mathrm{od}} / H_{\mathrm{os}}$, for a number of metallic materials, is presented 


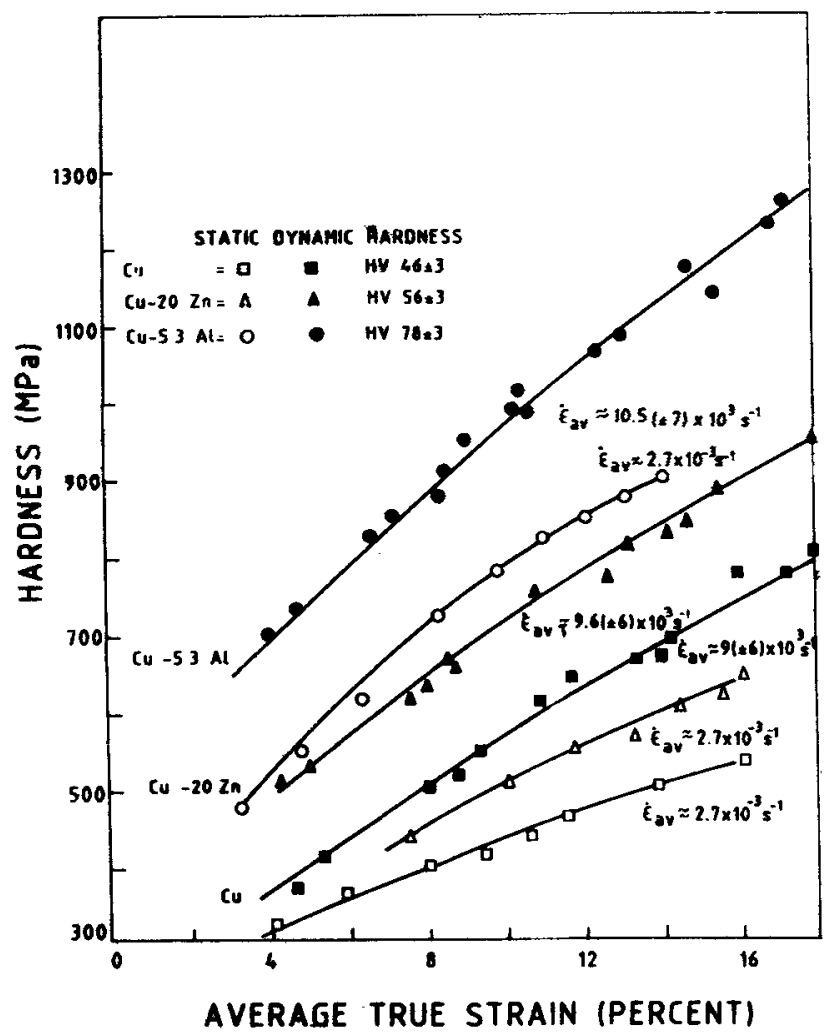

Figure 3. Variation of static and dynamic hardness as a function of average true strain for $\mathrm{Cu}, \mathrm{Cu}-20 \% \mathrm{Zn}$ and $\mathrm{Cu}-5 \cdot 3 \% \mathrm{Al}$ alloys.

in figure $6 \mathrm{~b}$. The trend of the data is broadly similar to that of the ratio $H_{\mathrm{d}} / H_{s}$ (figure 6a). The only significant difference is that in the case of precipitation and dispersion hardened alloys like A1 7039 and MA 754, the ratio $H_{\mathrm{od}} / H_{\mathrm{os}}<1$. Since, $H_{\text {od }}$ and $H_{o s}$ are characteristic of material strength at large strains, the implication is that the positive strain rate sensitivity with respect to hardness disappears or even becomes negative at large strains.

In figure 7, the $n_{\mathrm{d}}$ and $n_{\mathrm{M}}$ values (defined by (8) and (9)) are compared for a variety of metallic materials. In the case of pure fcc metals like $\mathrm{Ni}$ and $\mathrm{Cu}$, $n_{\mathrm{d}}>n_{\mathrm{M}}$ and thus these materials exhibit increased strain hardening capability at dynamic strain rates. Solid solutions of fcc metals $(\mathrm{Cu}-\mathrm{Zn}, \mathrm{Cu}-\mathrm{Al}, \mathrm{Ni}-\mathrm{Cr}$ and $\mathrm{Al}$ 7039 alloy) are characterized by nearly the same $n_{M}$ and $n_{d}$ values. In contrast, bcc metals (Fe) and dispersion strengthened alloys (MA 754) exhibit a lower strain hardening capability at dynamic strain rates, i.e. $n_{\mathrm{d}}<n_{\mathrm{M}}$. Pure $\mathrm{Al}$, though a fcc metal, also behaves like a bcc metal most probably due to its high stacking fault energy (unlike $\mathrm{Cu}$ or $\mathrm{Ni}$ ).

\subsection{Assumptions and their validity}

2.4a Tabor relation for average strain: In the case of both the static and dynamic 


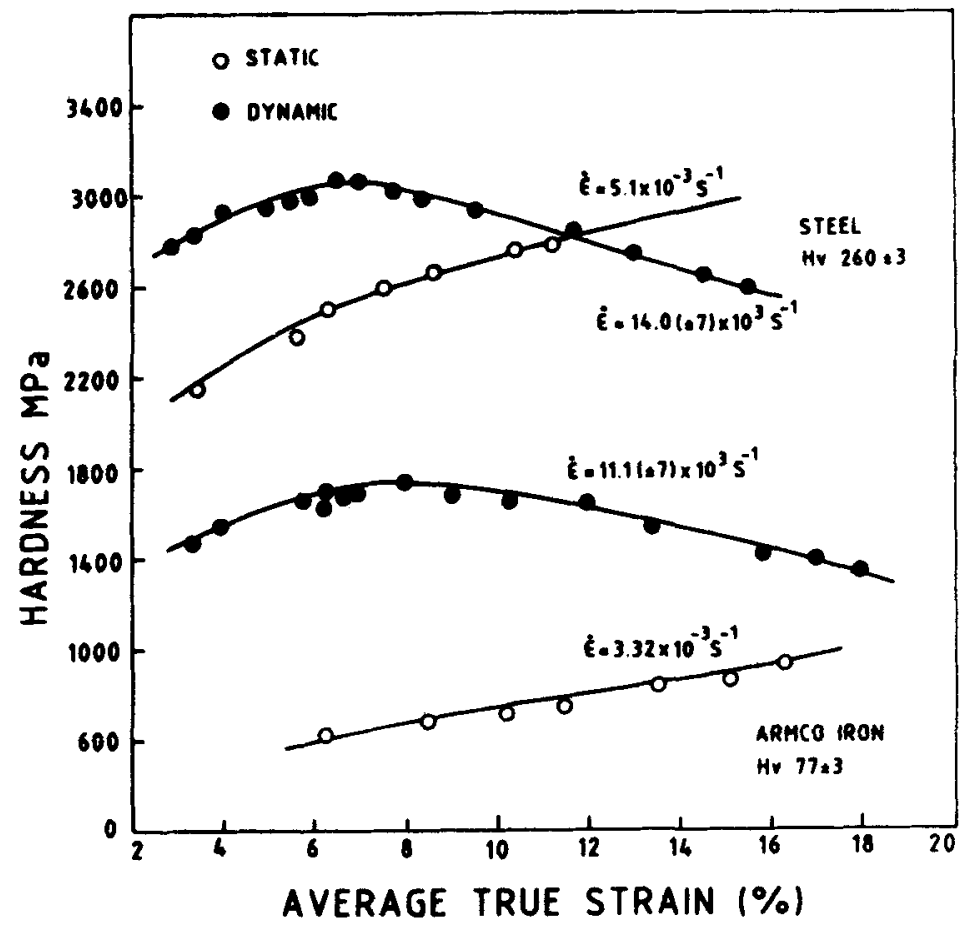

Figure 4. Variation of static and dynamic hardness as a function of average true strain lor iron and steel Bl (Hv 260).

hardness tests, a key assumption is that the Tabor relation (4) can be utilized for estimating the average strain $\left(\varepsilon_{\mathrm{av}}\right)$ in the plastic zone formed underneath the indentor. The above assumption is shown to be valid, in this section on the basis of a simple energy-based analysis.

Assume the shape and size of the plastic zone formed beneath the indent, in the test material, as illustrated in figure 8 . The plastic zone can be modelled with adequate accuracy as a hemisphere of radius $\beta(W / 2)(W$, indent diameter). If we further assume the following constitutive equation for plastic flow,

$$
\sigma=K \varepsilon_{a v},
$$

where $\sigma$ is the flow stress, $\varepsilon_{a v}$ the pl.sstic strain, $K$ the strength coefficient and $n$ the strain hardening exponent, then the energy dissipated in the plastic zone $\left(E_{\mathrm{pl}}\right)$ through plastic flow is obtained as (Tirupataiah and Sundararajan 1991b),

$$
E_{\mathrm{pl}}=(\pi / 12) \beta^{3} W^{3} K \varepsilon_{\mathrm{ux}} / n+1
$$

The energy expended by the indentor as it forms the indent $\left(E_{\text {ind }}\right)$ is given as (Tirupataiah and Sundararajan 1991b),

$$
E_{\text {ind }}=C \cdot K \varepsilon_{\mathrm{av}}\left(\pi W^{4} / 32 D\right) \text {, }
$$




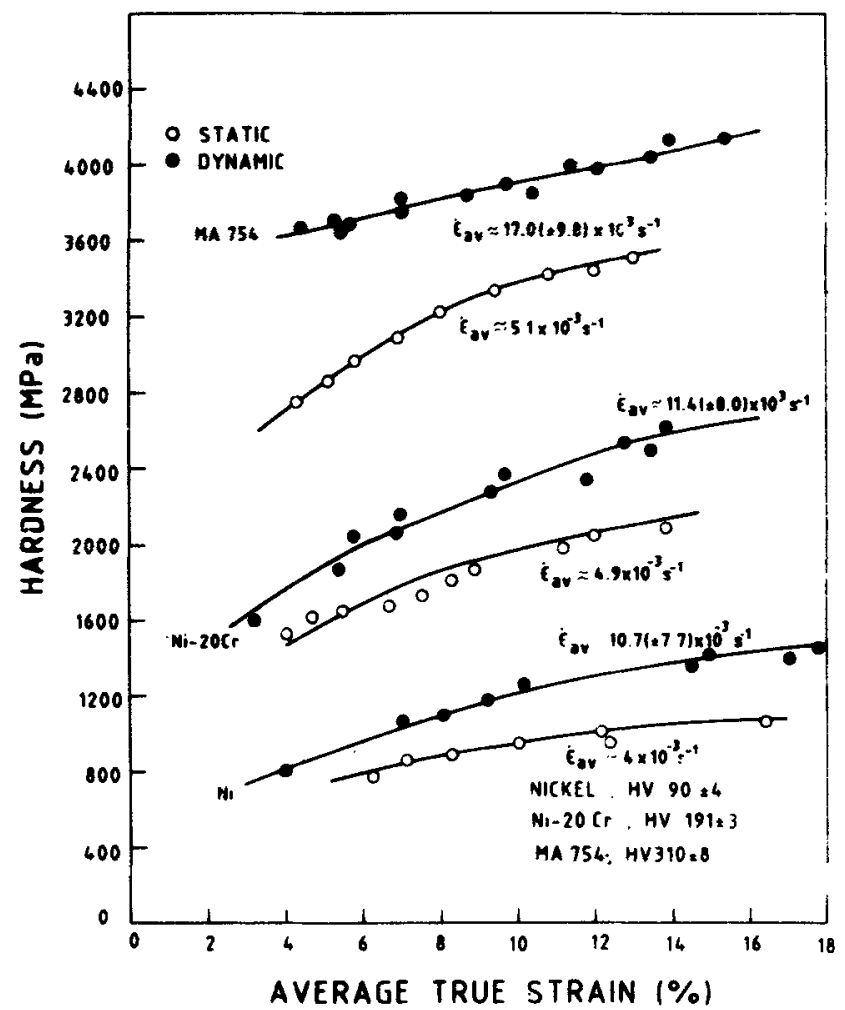

Figure 5. Variation of static and dynamic hardness as a function of average true strain for $\mathrm{Ni}, \mathrm{Ni}-20 \% \mathrm{Cr}$ and $\mathrm{MA} 754$ alloy.

where $C$ is the constraint factor defined earlier (2), $D$ the ball diameter and the term within the brackets represents the indent volume. Since (11) and (12) should be equal to each other, $\varepsilon_{\mathrm{av}}$ can be obtained as,

$$
\varepsilon_{\mathrm{av}}=(3 / 8)\left[C(n+1) / \beta^{3}\right](W / D) \text {. }
$$

It can be seen that (13) is identical to the Tabor relation (4) and in fact gives additional information on the parameters which have bearing on the numerical constant of 0.2 in (4). The main conclusion from the above analysis is that as long as the plastic zone scales as the indent diameter, the Tabor relation for $\varepsilon_{\mathrm{av}}$ should be valid.

In figure 9 , the variation of the parameter $\beta\left(=\left(L_{1}+0.5 W\right) / 0.5 W=\left(L_{2}+d\right) /\right.$ $0.5 \mathrm{~W}$, see figure 8) with $\varepsilon_{\mathrm{av}}$ is plotted for a large number of materials. The values of $L_{1}$ and/or $L_{2}$ were measured for each indent either through lip height measurements using surface profilometer or through microhardness-depth profiles carried out on surfaces sectioned perpendicular to and along the diameter of the indent (Tirupataiah and Sundararajan 1987). The filled and unfilled symbols represent the $\beta$ values measured on dynamically and statically formed indents respectively. It is clear from figure 9 that $\beta$ is, to a very good approximation, independent of both $\varepsilon_{\mathrm{av}}$ and the 


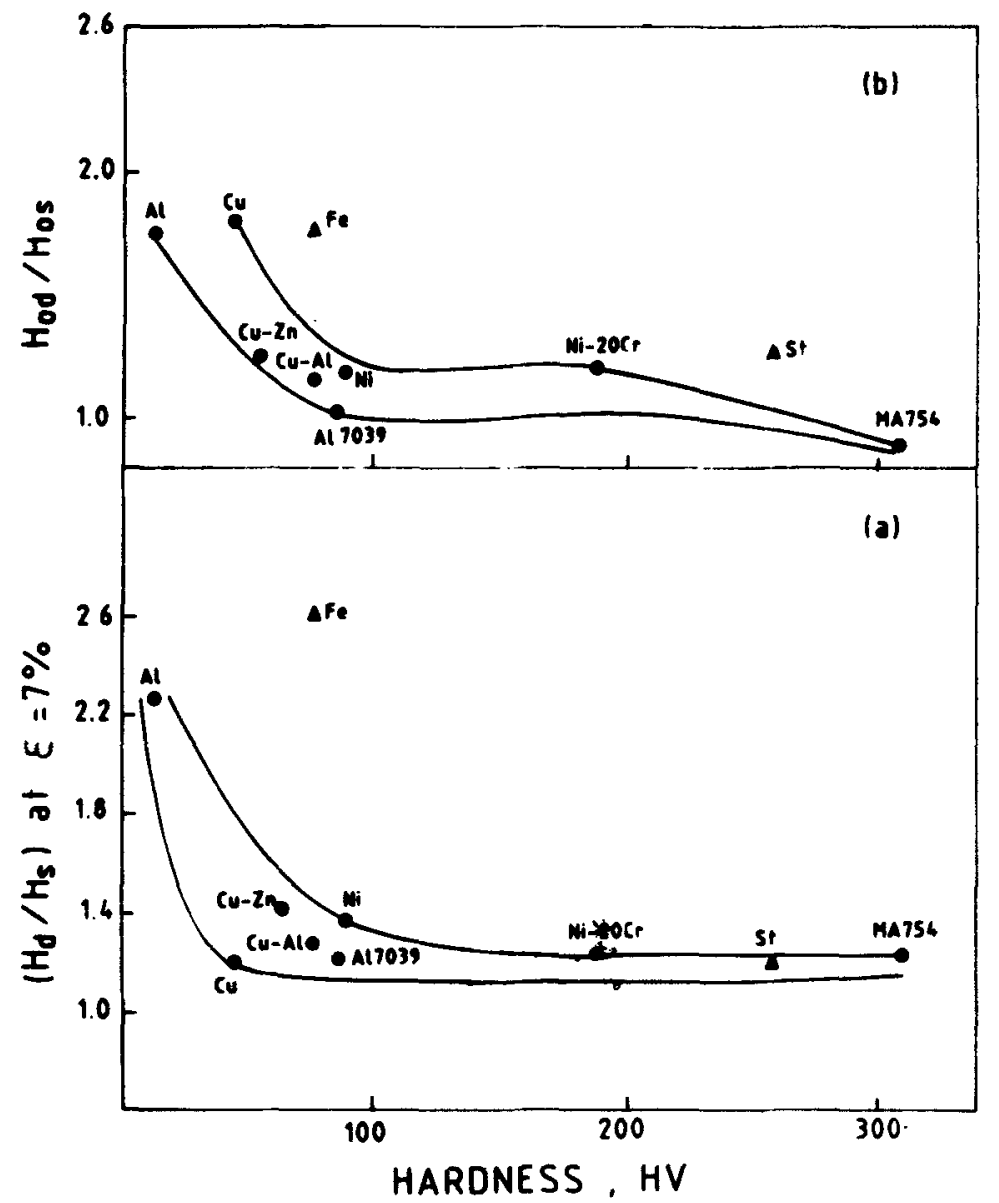

Figure 6. (a) The ratio of dynamic to static hardness $\left(H_{\mathrm{J}} H_{s}\right)$ at a constant strain of $7 \%$ for a number of metallic materials and (b) the ratio $H_{0 d} / H_{0 s}$ (defined by (8) and (9) in the text) for a number of metallic materials.

test material. Figure 9 thus demonstrates the validity of the Tabor relation for $\varepsilon_{\mathrm{av}}(4)$ under both static and dynamic indentation conditions.

2.4b Negligible deformation of the ball: Under static indentation conditions, it is well known that the ball hardness should be atleast twice the hardness of the test material, for a valid hardness test. In contrast, under dynamic indentation conditions, it is not clear as to how much harder the impacting ball should be in comparison to the hardness of the test material. To answer the question, a series of dynamic indentation tests were carried out with a variety of balls $(W C$, steel, ceramic and nylon) having a wide range of hardness ( $\mathrm{Hv} 9$ to $\mathrm{Hv} 2018$ ) (Tirupataiah and Sundararajan 1990). A steel of hardness $\mathrm{Hv} 551$ was used as the test material and indentations were carried out over a range of impact velocities. For each of the indentation tests carried out, the crater volume $\left(V_{\mathrm{c}}\right)$, dynamic hardness $\left(H_{\mathrm{d}}\right)$ and average strain $\left(\varepsilon_{\mathrm{av}}\right)$ were determined using (5), (6) and (4) respectively. The results 


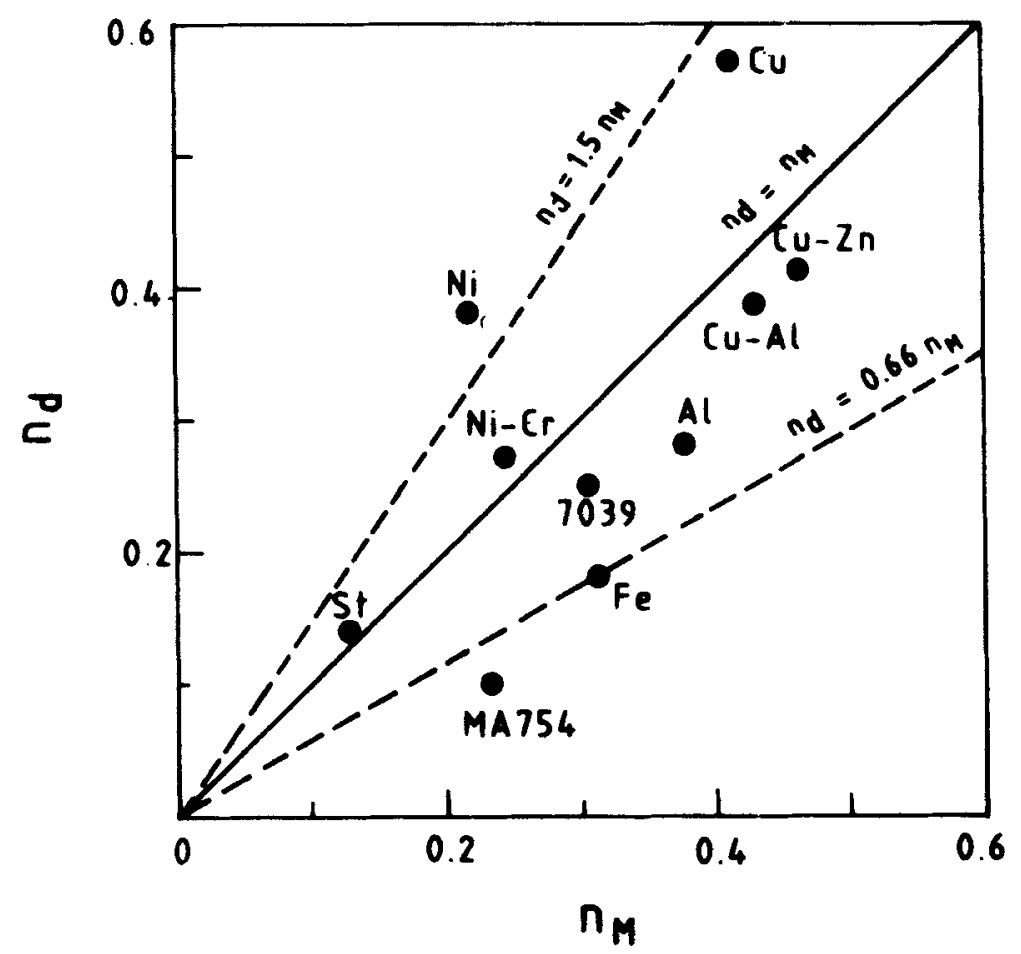

Figure 7. A comparison of static and dynamic strain hardening exponents $\left(n_{M}\right.$ and $n_{d}$ respectively) for a number of metals and alloys.

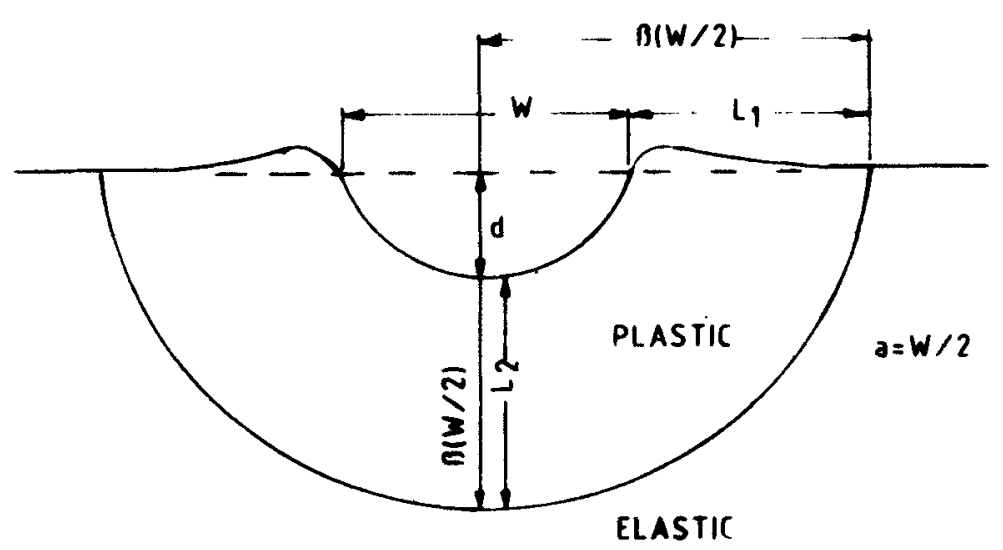

Figure 8. A schematic diagram of the plastic zone with the various parameters defined.

are presented in figure 10 . The variation of the normalized crater volume with the ratio of the hardness of the ball to that of the test material is illustrated in figure 10a for various constant values of kinetic energy of the impacting ball. Similarly, the ratio $H_{\mathrm{d}}$ (different ball) $/ H_{\mathrm{d}}$ (WC ball) is plotted against $\mathrm{Hv}$ (ball)/ $\mathrm{Hv}$ (test 


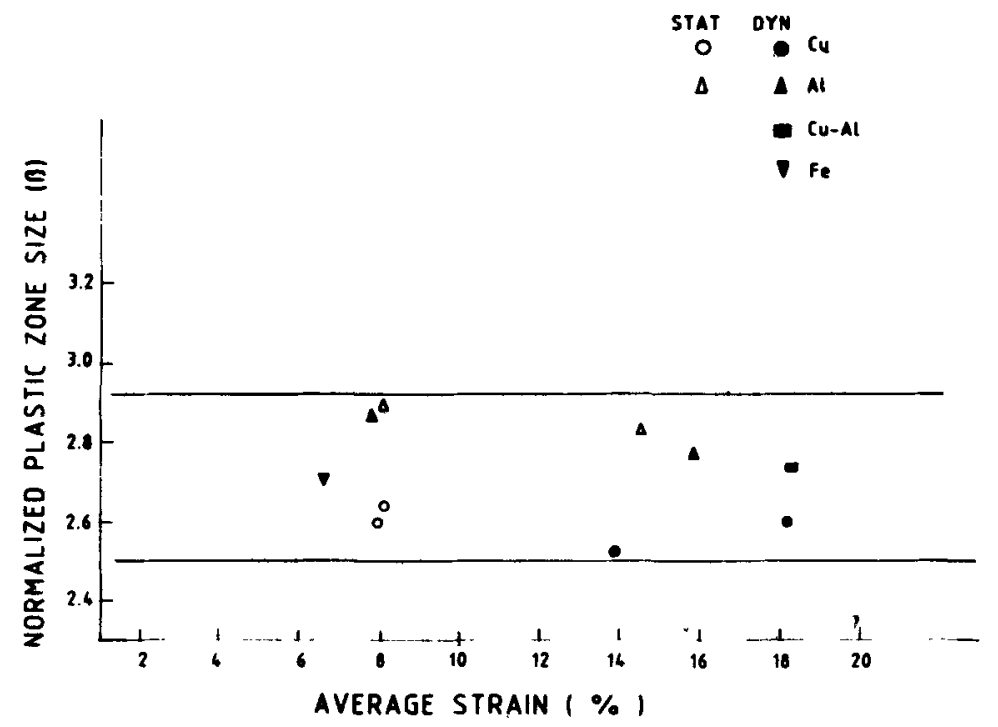

Figure 9. The variation of the normalized plastic zone size $(\beta)$ with average strain $\left(\varepsilon_{\mathrm{av}}\right)$ for a number of materials. The filled and unfilled symbols represent dynamic and static indentation data respectively.

material) in figure $10 \mathrm{~b}$ at various constant levels of $\varepsilon_{\mathrm{av}}$. It is clear from both the figures $10 a$ and $b$ that if the hardness of the ball is less than about 1.5 times the hardness of the test material, the crater volume shows a decrease and correspondingly $H_{\mathrm{d}}$ shows a dramatic increase with decreasing hardness ratio. Such a trend in data is consistent with the ball undergoing plastic deformation during indentation. Thus, it can be concluded that the rule of thumb valid for static hardness tests, viz. that the hardness of the ball should be atleast twice the hardness of the test material, is equally valid for dynamic hardness tests.

\section{Flow stress-strain relationship}

\subsection{Introduction}

In the last section, the procedure for obtaining the hardness-strain relationship in the case of metallic materials was described. The transformation of $H-\varepsilon_{\mathrm{av}}$ curves to flow stress $(\sigma)$-strain $(\varepsilon)$ curves requires information on the constraint factor (C) described earlier (2). The relationship between the $H-\varepsilon_{\mathrm{av}}$ and $\sigma-\varepsilon$ curves is schematically illustrated in figure 11 . Thus, $H$ and $\sigma$ are related to each other, at a given strain $(\varepsilon)$ given below

$$
H(\varepsilon)=C \sigma(\varepsilon)
$$

Ideally, $C$ should be independent of strain for a given material as shown in figure 11. Further, if $C$ is also reasonably. independent of the test material properties, then a constant value for $C$ can be used to convert the $H-\varepsilon$ curve of any material 

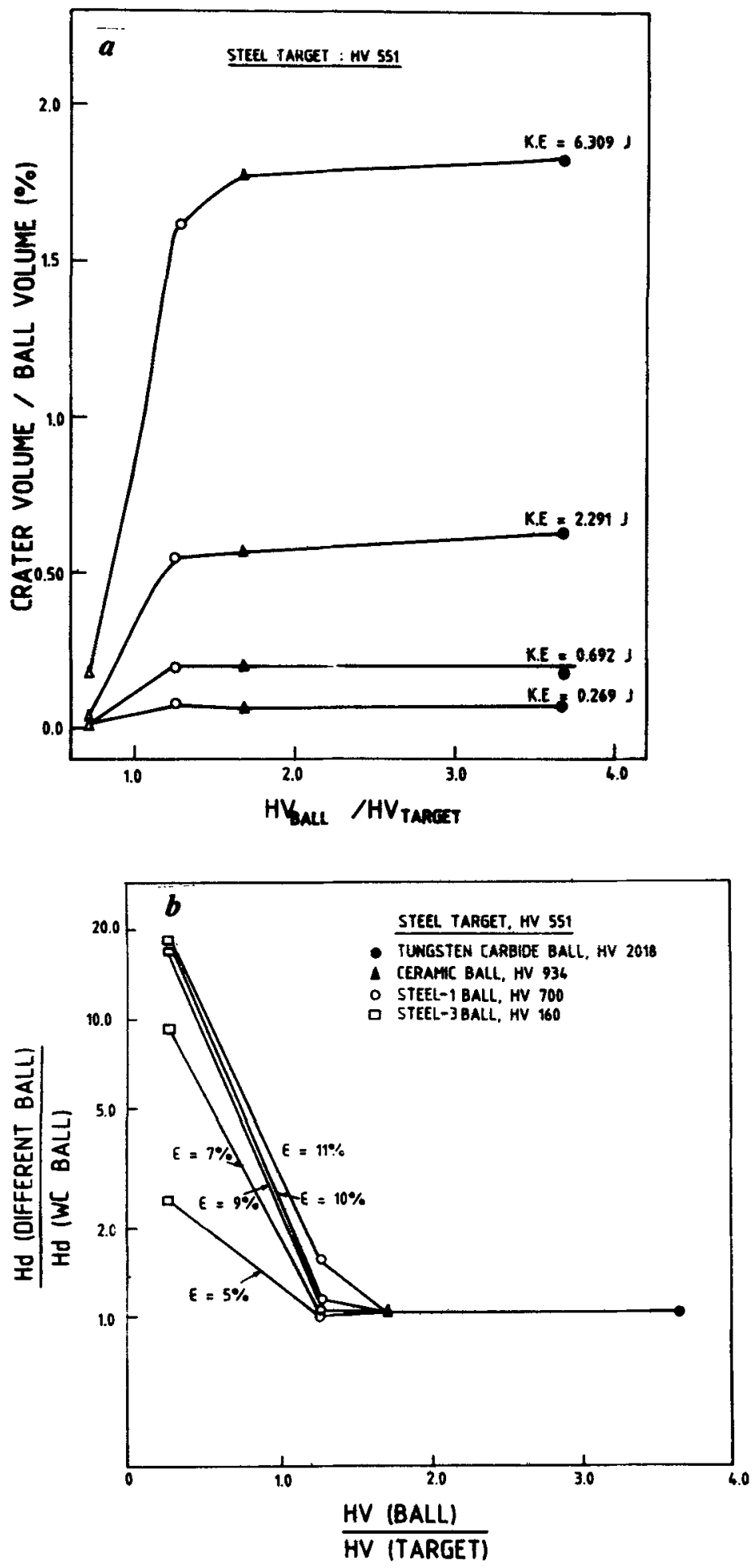
to the corresponding flow stress-strain curve. In fact, many of the investigators have made such an assumption and have utilized a value in the range 2.8 to 3 for $C$ (Francis 1976). But as will be shown subsequently, $C$ is not really independent of the test material properties and further under certain indentation conditions, $C$ is also a function of strain. Therefore, it is important that the indentation test conditions under which the concept of the constraint factor can be effectively utilized to obtain $\sigma-\varepsilon$ curves, be clearly defined and demarcated.

\subsection{Experimental determination of $\dot{C}$}

To investigate the dependence of the constraint factor $(C)$ on strain and test material properties, $C$ has to be experimentally determined through independent hardness and tensile/compression tests on the same material. As illustrated in figure 11, if $H_{\mathrm{s}}-\varepsilon_{\mathrm{av}}$ curve is determined using hardness test and the $\sigma-\varepsilon$ relation through tensile or compression tests, $C$ can be determined at different constant levels of strain.

Figures 12 and 13 illustrate the experimental $H_{\mathrm{s}}-\varepsilon_{\mathrm{av}}$ and $\sigma-\varepsilon$ curves in the case of copper and iron respectively. In these figures, the full line joining the unfilled circles represent the $H_{\mathrm{s}}-\varepsilon_{\mathrm{ay}}$ curve while the full line and the dashed line represent the compressive and tensile $\sigma-\varepsilon$ curves respectively. As to be expected, the tensile and compressive $\sigma-\varepsilon$ curves lie very close to each other. In the same figures 12 and 13 , the filled circles represent the $\sigma$ points obtained by dividing $H_{\mathrm{s}}$ by $C$ where $C$ equals 2.42 for $\mathrm{Cu}$ and 2.61 for iron. It is clear that the $\sigma$ values obtained by assuming a constant value for $C$, independent of strain, correspond very well with the $\sigma-\varepsilon$ curves obtained from tensile and compression tests.

\subsection{Constraint factor and strain}

In the case of copper and iron, the constraint factor $(C)$ appears to be independent of strain as can be noted from figures 12 and 13. However, the above assumption does not hold for a number of test materials as can be observed from figures 14, 15 and 16. In each of these figures, $C$ is plotted as a function of $\varepsilon_{a v}$. In the case of $\mathrm{Cu}, \mathrm{Cu}-\mathrm{Zn}$ and $\mathrm{Cu}-\mathrm{Al}$ alloys, $C$ is independent of strain (figure 14). In contrast, in the case of steels (figure 15), $C$ increases with increasing strain at low strains but becomes independent of strain at large strains. In the case of an Al 7039 alloy, $C$ is independent of strain when the alloy is tested in the solution treated condition (figure 16c). However, in the aged and overaged conditions, $C$ increases with strain at low strains and then becomes a constant (figures 16a and $b$ ).

On the basis of the $C-\varepsilon$ behaviour illustrated in figures 14 to 16 , a transition strain $\left(\varepsilon_{\mathrm{tr}}\right)$ can be defined. For $\varepsilon<\varepsilon_{\mathrm{tr}}, C$ increases with increasing strain while for $\varepsilon \geq \varepsilon_{\mathrm{tr}}, C$ is independent of strain. The above transition behaviour is related to the

Figure 10. (a) The variation of crater volume normalized by the ball volume as a function of the ratio ball hardness to target hardness for a steel target at four different constant kinetic energy values and (b) the variation of dynamic hardness of steel target obtained using different balls normalized by the dynamic hardness obtained using WC ball, as a function of the ratio of the ball hardness to target hardness, for WC, ceramic, steel 1 (Hv 700) and steel 3 (Hv 160) balls. 


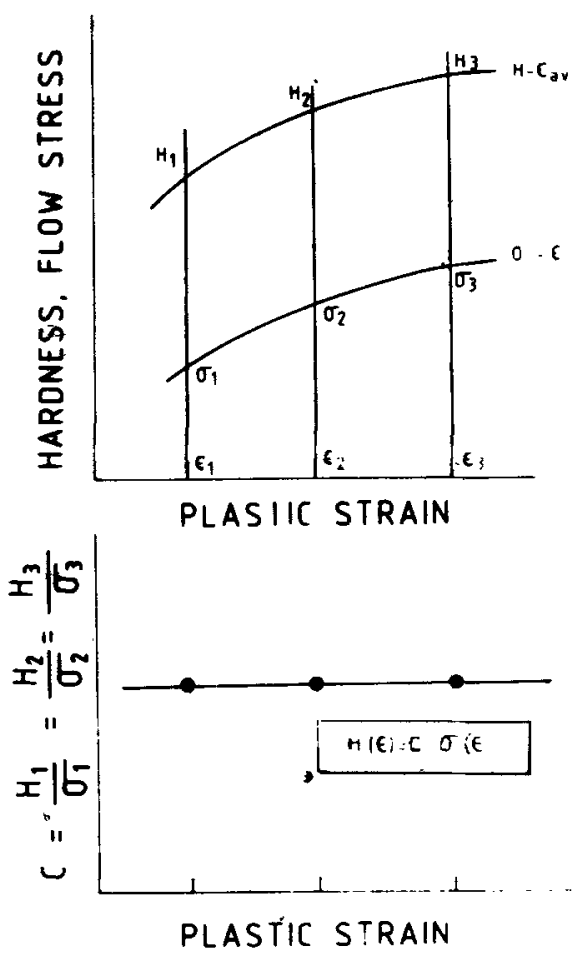

Figure 11. A schematic diagram illustrating the relationship between the $H-\varepsilon_{a v}$ and the $\sigma-\varepsilon$ curves through the constraint factor $(C)$.

transition of the valid indentation model from the elastic-plastic model at low strains $\left(\varepsilon<\varepsilon_{\mathrm{tr}}\right)$ to the fully plastic model at large strains $\left(\geq \varepsilon_{\mathrm{t}}\right)$. An expression for the above transition strain $\left(\varepsilon_{\mathrm{tr}}\right)$ can be obtained as (Tirupataiah and Sundararajan 1991b),

$$
\varepsilon_{\mathrm{ur}}=\left(9 K / E_{\mathrm{e}}\right)^{1 / 1-n}
$$

In (15), $K$ and $n$ are defined by (10) and $E_{e}$ is the effective modulus of the indenter-test material system and is given as,

$$
E_{\mathrm{c}}=E E_{\mathrm{b}} /\left[E\left(1-\mathrm{v}_{\mathrm{b}}\right)+E_{\mathrm{b}}\left(1-v^{2}\right)\right]
$$

In (16), $E$ and $v$ are the elastic modulus and Poissons ratio respectively of the test material while $E_{\mathrm{b}}$ and $v_{\mathrm{b}}$ are the corresponding values for the ball material.

To conclude, as long as the average strain introduced in the plastic zone exceeds $\varepsilon_{t r}$, it is reasonable to assume a strain independent value for $C$.

\subsection{Constraint factor and material properties}

In the last section it has been shown that for any test material, an appropriate 


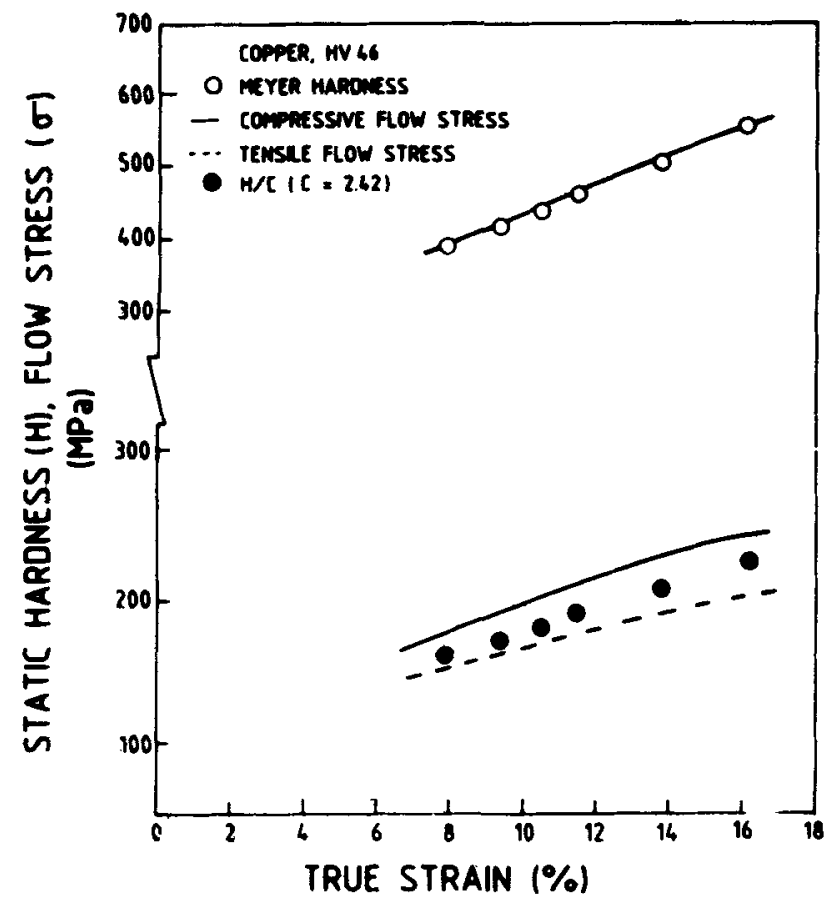

Figure 12. The experimental $H_{\mathrm{s}}-\varepsilon_{\mathrm{av}}$ and $\sigma-\varepsilon$ curves for copper. The filled circles represent the $\sigma-\varepsilon$ data derived from $H_{5}-\varepsilon_{\mathrm{av}}$ curve.

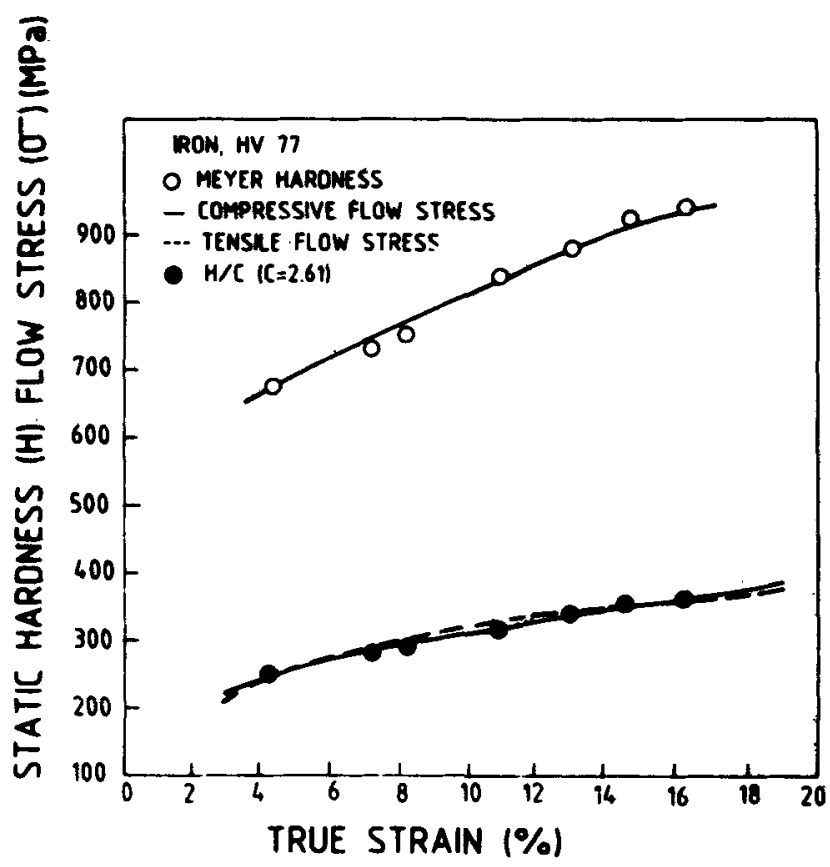

Figure 13. The experimental $H_{\mathrm{s}}-\varepsilon_{\mathrm{av}}$ and $\sigma-\varepsilon$ curves for iron. The filled circles represent the $\sigma-\varepsilon$ data derived from $H_{5}-\varepsilon_{a y}$ curve. 

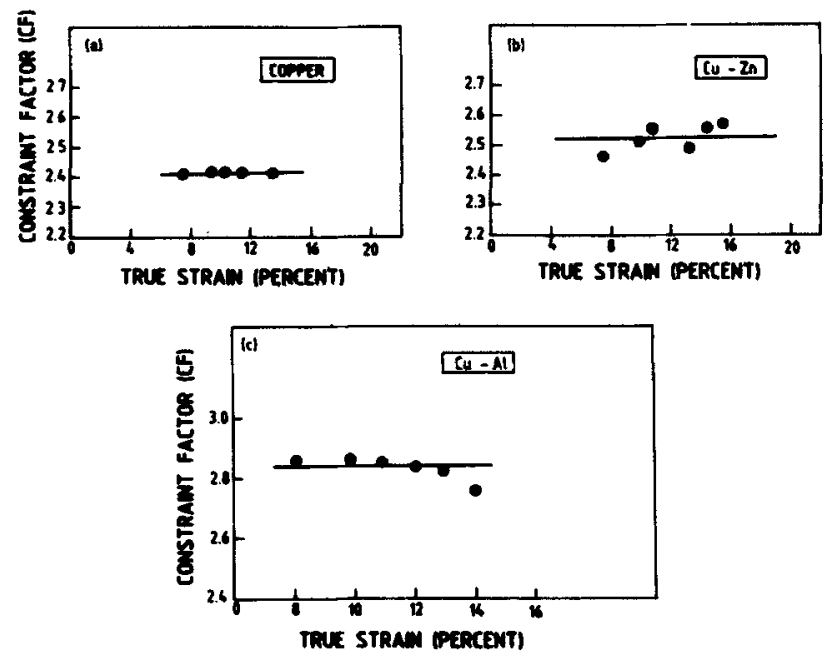

Figure 14. The variation of constraint factor with average true strain: (a) copper, (b) $\mathrm{Cu}-\mathrm{Zn}$ alloy and (c) $\mathrm{Cu}-\mathrm{Al}$ alloy.
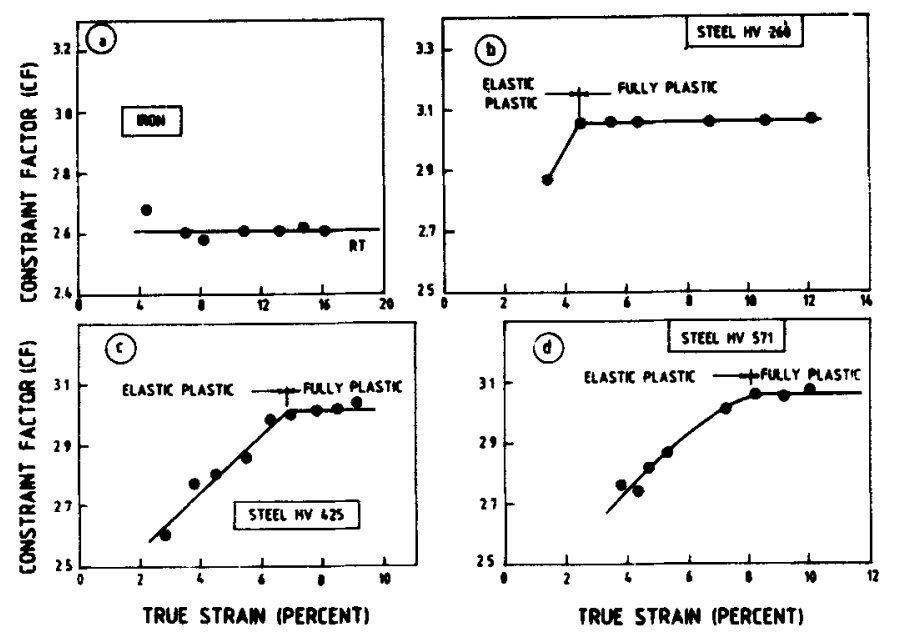

Figure 15. The variation of constraint factor with true strain: (a) iron, (b) steel, Hv 260; (c) steel, Hv 425; and (d) steel, Hv 571.

strain regime $\left(>\varepsilon_{t r}\right)$ can be defined wherein $C$ is independent of strain. The next question is related to the magnitude of $C$ (for $\varepsilon \geq \varepsilon_{\mathrm{tr}}$ ) and the manner in which the test material properties (like $K$ and $n$ ) influence $C$.

In table 1 , the value of $C$ (for $\varepsilon \geq \varepsilon_{\mathrm{tr}}$ ) is listed for 16 test materials along with their mechanical property values. The first point to be noted from table 1 is that the value of $C$ varies from 2.25 for $\mathrm{Al}$ to 3.06 for steel of hardness $\mathrm{Hv} \mathrm{571.} \mathrm{Thus,}$ $C$ is certainly a material dependent parameter.

To elucidate more clearly the influence of material parameters on $C$, the variation of $C$ with the strain hardening exponent $(n)$ is presented in figure 17. The 
experimental values of $C$ (from table 1) are indicated as filled circles while the value of $C$ predicted by the equation due to Mathews (1980), given below is represented by the full line

$$
C=(3 / 1+0.5 n)(1.415)^{n}
$$

It is clear from figure 17 that majoritv of the data points fit (17). However, there
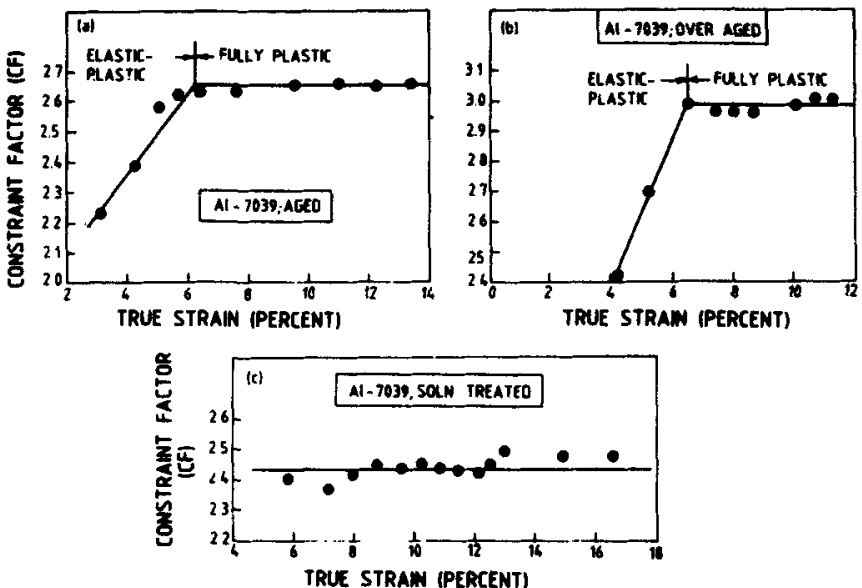

Figure 16. The variation of constraint factor of an Al 7039 alloy with true strain: (a) aged, (b) overaged and (c) solution treated.

Table 1. The experimentally obtained constraint factors and mechanical properties.

\begin{tabular}{lrrrl}
\hline Material & $\begin{array}{c}\text { Hardness } \\
\left(\mathrm{Hv} ; \mathrm{kg} / \mathrm{mm}^{2}\right)\end{array}$ & $\begin{array}{c}\text { Constraint } \\
\text { factor }(C)\end{array}$ & $\begin{array}{c}K \\
(\mathrm{MPa})\end{array}$ & $n$ \\
\hline Copper (Cu) & $46 \pm 3$ & 2.41 & 512 & 0.45 \\
Cu-20 Zn & $56 \pm 2$ & 2.52 & 595 & 0.485 \\
Cu-5.3 Al & $78 \pm 3$ & 2.84 & 915 & 0.52 \\
Nickel (Ni) & $90 \pm 4$ & 2.87 & 490 & 0.20 \\
Iron & $77 \pm 3$ & 2.61 & 568 & 0.26 \\
Steel A 1 & $314 \pm 3$ & 2.93 & 1300 & 0.096 \\
Steel A 2 & $356 \pm 6$ & 2.92 & 1375 & 0.07 \\
Steel A 3 & $487 \pm 6$ & 2.90 & 1860 & 0.049 \\
Steel A 4 & $569 \pm 8$ & 3.01 & 2213 & 0.056 \\
Steel B 1 & $260 \pm 3$ & 3.06 & 1137 & 0.12 \\
Steel B 2 & $425 \pm 5$ & 3.00 & 1534 & 0.061 \\
Steel B 3 & $571 \pm 6$ & 3.06 & 2163 & 0.05 \\
Al & $14 \pm 1$ & 2.25 & 135 & 0.28 \\
Al 7039 (ST) & $86 \pm 2$ & 2.44 & 605 & 0.268 \\
Al 7039 (PA) & $169 \pm 3$ & 2.96 & 693 & 0.061 \\
Al 7039 (OA) & $112 \pm 3$ & 2.62 & 508 & 0.115 \\
\hline
\end{tabular}




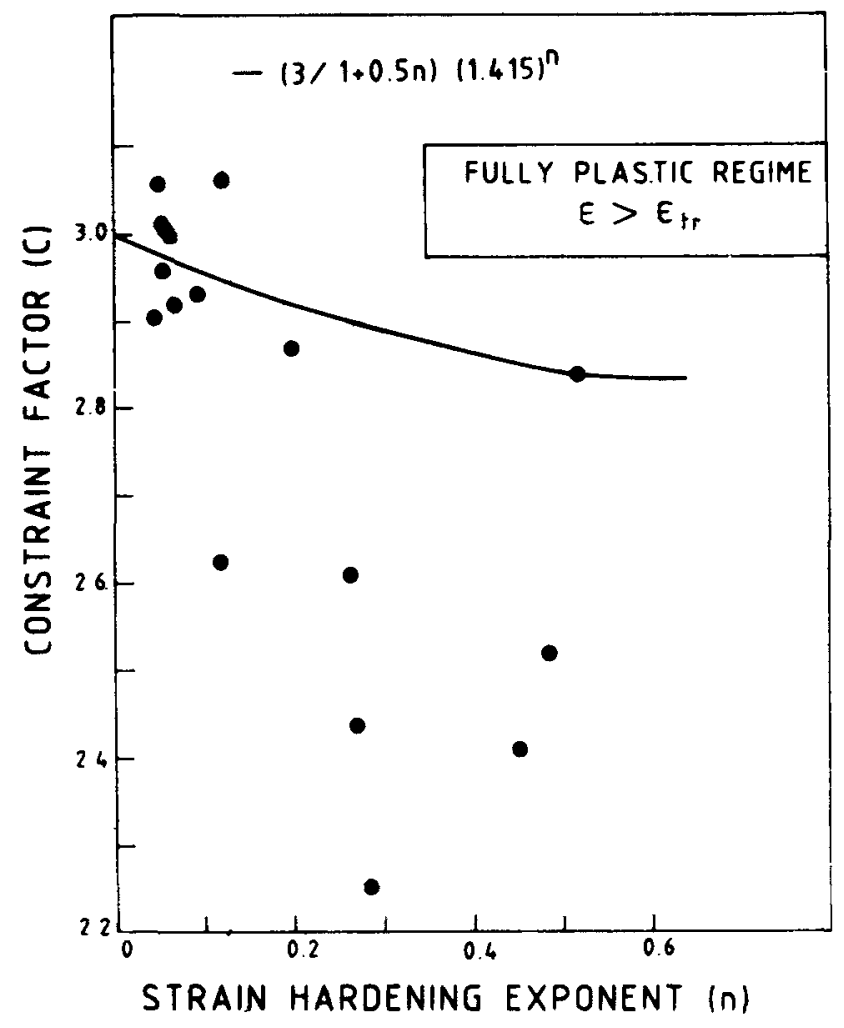

Figure 17. The variation of constraint factor $(C)$ with strain hardening exponent $(n)$. The value of $C$ predicted by Mathews ((17) in the text) is represented by the full line.

are 6 data points which lie well below the theoretical line. A perusal of these data points indicate that they pertain to materials with low $K$ values (see table 1) like $\mathrm{Cu}, \mathrm{Al}, \mathrm{Fe}, \mathrm{Cu}-\mathrm{Zn}, \mathrm{Al}-7039$ (ST) and Al-7039 (OA). To observe the effect of $K$ per se on $C$ more clearly, in figure 18, the ratio of experimental to predicted (17) value of $C$ is plotted as a function of $K$. Figure 18 brings out the $K$ effect very clearly and in fact suggests that $K$ has an influence on $C$ only when $K \leq 900$ $\mathrm{MPa}$.

The influence of $n$ and $K$, demonstrated by figures 17 and 18, can be combined to give the following empirical expressions for $C$.

$$
\begin{aligned}
& C=(3 / 1+0.5 n)(K(\mathrm{MPa}) / 900)^{n / 2}(1.415)^{n} \text { for } K<900 \mathrm{MPa}, \\
& C=(3 / 1+0.5 n)(1.415)^{n} \text { for } K \geq 900 \mathrm{MPa} .
\end{aligned}
$$

The values of $C$ predicted by (18) and (19), for all the test materials listed in table 1 , is compared with the corresponding experimental values of $C$ in figure 19. In this figure the diagonal line represents the perfect matching between the predicted and experimental values. It is obvious from figure 19 that (18) and (19) have the capability to predict $C$ values for a wide range of materials within $\pm 10 \%$. 


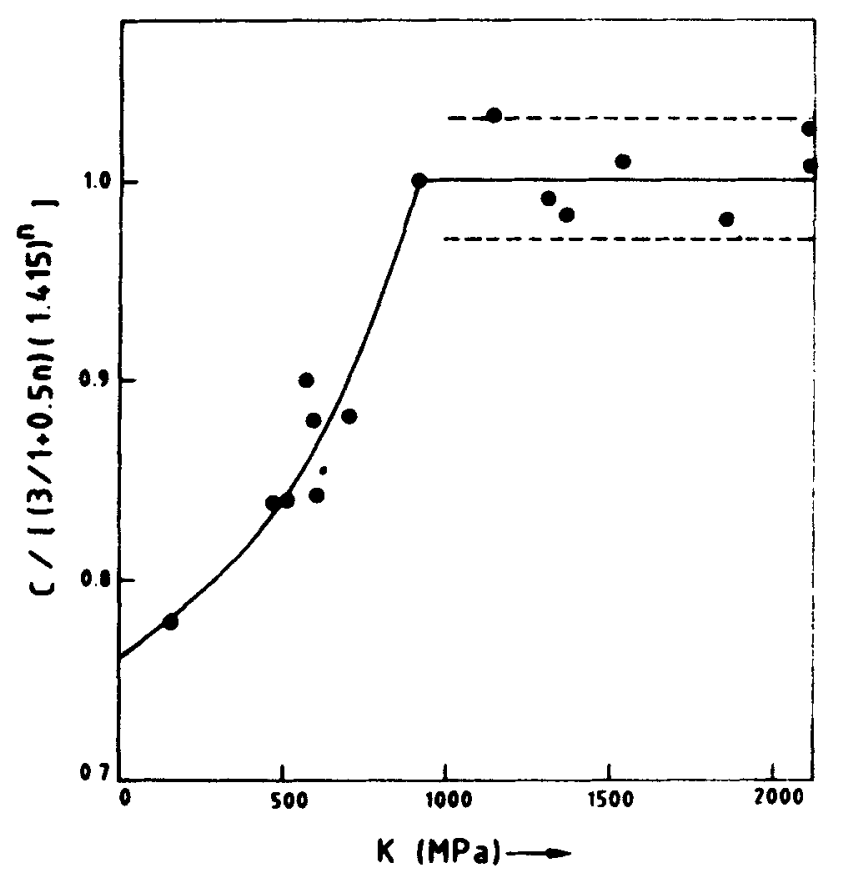

Figure 18. The variation of the ratio of experimental value of $C$ (table 1 ) to the predicted value of $C(17)$ with the strength coefficient $(K)$.

\subsection{Constraint factor at high strain rates}

All the discussions pertaining to $C$ has so far dealt with only static indentation tests. On the other hand, it is not clear as to whether the concepts related to $C$, developed in $\$ \S 3.2$ to 3.4 , are equally valid under dynamic indentation conditions. It is demonstrated below, albeit in an indirect fashion, that the concepts related to $C$ are indeed valid even under high strain rate deformation conditions characteristic of dynamic indentation.

In figure 20 , the microhardness-depth profiles measured on surfaces, obtained by sectioning the indent formed on the test material along its diagonal, are presented for both static and dynamic indentations in the case of iron and copper. The main point to be noted in figure 20 is that the microhardness-depth profiles are nearly identical for both static and dynamic indents when the comparison is made at nearly the same average strain. Thus, it can be concluded that not only the size of the plastic zone (defined as $L$ in figure 20) but also the strain distribution within the plastic zone are identical irrespective of whether the indentation occurs under static or dynamic conditions. Figure 9, wherein the size of the normalized plastic zone is indicated for both static and dynamic indentations, also provides additional proof for the statement that the plastic zone size does not depend on whether the indentation is done under static or dynamic conditions. Since the energy dissipated in the plastic zone during indentation is largely a function of the plastic zone size and the strain distribution within the plastic zone (for a given material), it follows that $C$ should not be dependent on the indentation rate (i.e. static or dynamic). 


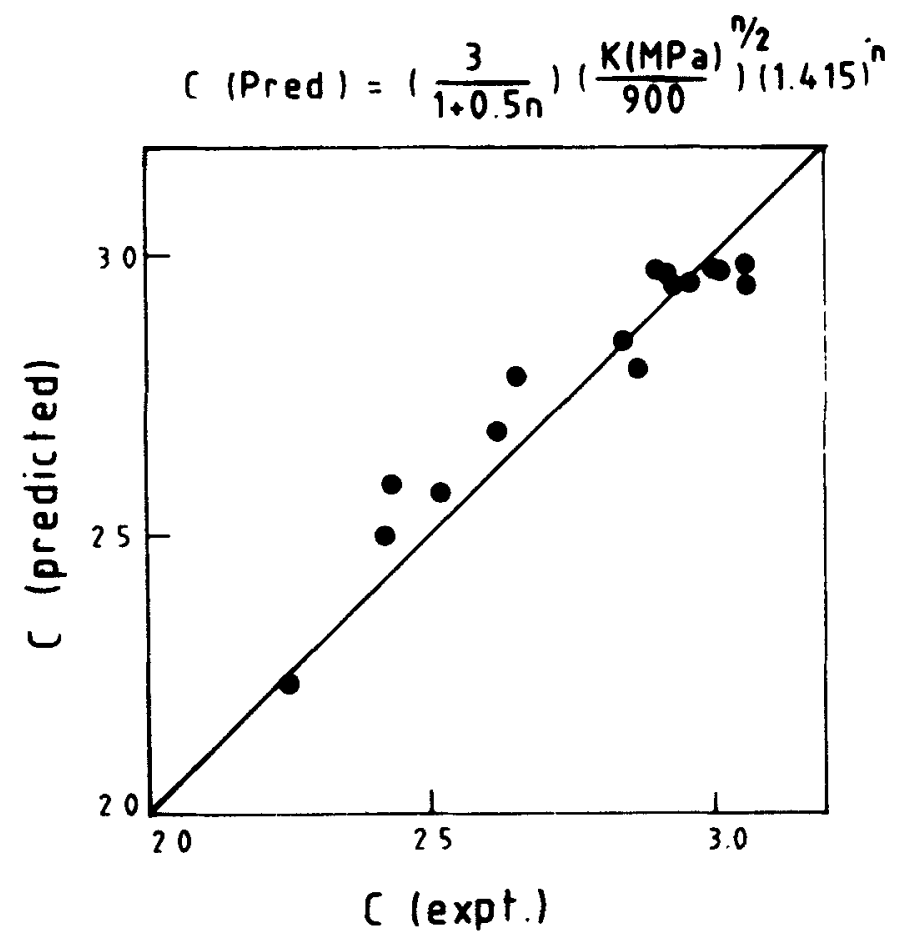

Figure 19. A comparison of the experimental value of $C$ (table 1 ) with the value of $C$ predicted by the empirical equations ((18) and (19) in the text) in the case of a number of metallic materials.

In figure 21 , the variation of the flow stress $(\sigma)$ of $\mathrm{Cu}$ with strain $(\varepsilon)$ is presented. The solid lines represent the static and dynamic $\sigma-\varepsilon$ curves of $\mathrm{Cu}$ derived from static and dynamic indentation tests respectively. The dashed line represents the static and dynamic $\sigma-\varepsilon$ curves of $\mathrm{Cu}$ obtained by Follansbee and Kocks (1988) utilizing tensile test and split Hopkinson pressure bar test respectively. The figure shows that the $\sigma-\varepsilon$ curves derived from indentation tests compare very well with the data of Follansbee and Kocks (1988). Since the same value of 2.41 was used for $C$ while deriving both the dynamic and static $\sigma-\varepsilon$ curves from the corresponding hardness-strain curves, the data presented in figure 21 provides additional proof for our assumption that $C$ is not a function of indentation rate.

In the case of static indentations, $C$ is independent of strain for $\varepsilon>\varepsilon_{\mathrm{tr}}$ (15). A similar condition applies for dynamic indentations as well. However, an additional restriction manifests itself during dynamic indentation. As demonstrated elsewhere (Tirupataiah and Sundararajan 1991a), beyond a critical strain $\left(\varepsilon_{c}\right)$, the plastic zone starts decreasing in size with increasing strain due to the onset of localization of plastic flow. Once the localization of plastic zone occurs, the $H_{\mathrm{d}}-\varepsilon$ curve which usually increases with increasing strain shows a downturn (see figure 5 for example) and the constraint factor also starts decreasing. Further, the Tabor relation for $\varepsilon_{\mathrm{av}}$ is no longer applicable under such conditions. As shown in an earlier publication (Tirupataiah and Sundararajan 1991a), the expression for $\varepsilon_{\mathrm{c}}$ is obtained as,

$$
\varepsilon_{\mathrm{c}}=[n A / C]^{1 / n+1} ; A=\rho_{\mathrm{t}} C_{\mathrm{p}} T_{\mathrm{m}} / K
$$




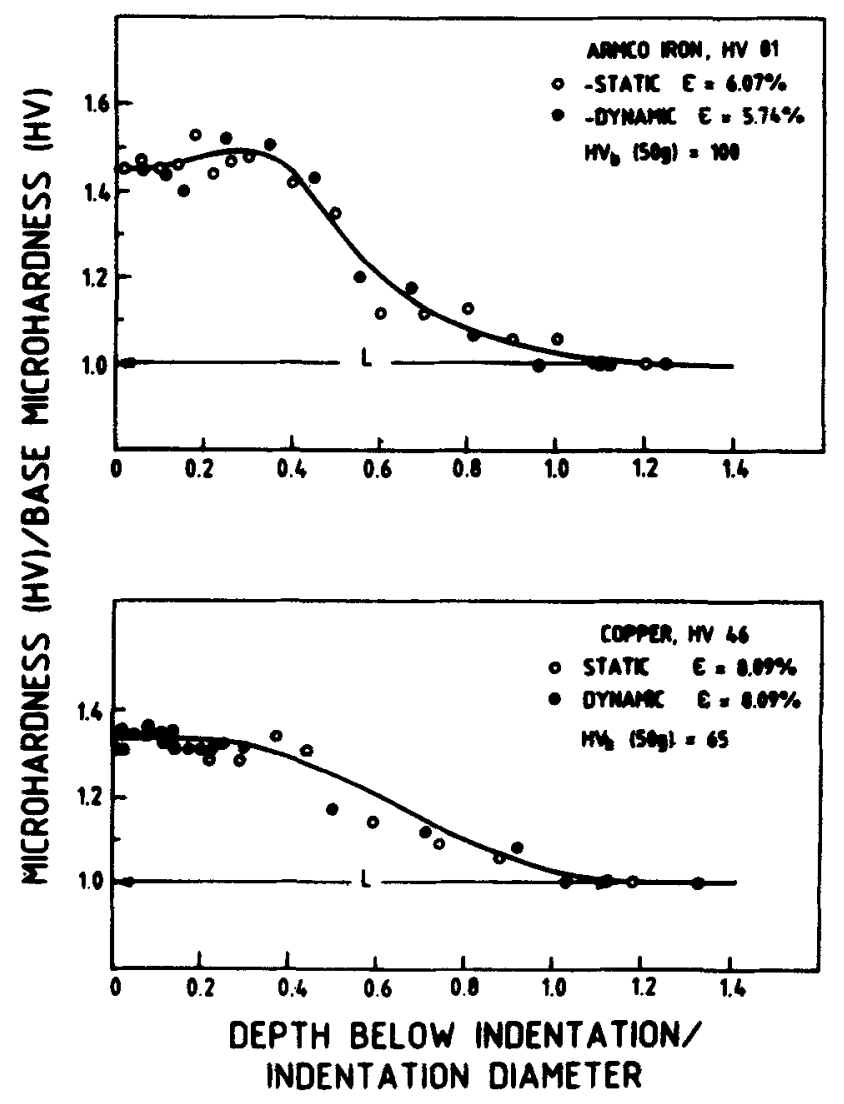

Figure 20. The microhardness-depth profiles obtained on statically and dynamically indented samples of iron and copper. In each of these profiles, the filled and unfilled symbols represent microhardness data obtained on dynamically and statically indented samples to neariy the same average strain.

In (20), $C$ is the normalized temperature depentence of flow stress $(\sim 0.5$ for many metals) and $\rho_{\mathrm{r}}, C_{\mathrm{p}}$ and $T_{\mathrm{m}}$ represent the density, specific heat and melting point respectively of the test material. In figure 22 , the values of $\varepsilon_{c}$ predicted by (20) is presented for a number of metallic materials. In general, lower the $K$ value and higher the $n$ value, higher is the $\varepsilon_{c}$ value.

\subsection{Test conditions for strain independent $C$}

In earlier sections, it has been shown that the average strain induced during indentation (static or dynamic) should exceed $\varepsilon_{\mathrm{tr}}$ (15) for $C$ to be independent of strain. In the case of dynamic indentation, an additional constraint for $C \neq f\left(\varepsilon_{\mathrm{av}}\right)$ is that $\varepsilon_{\mathrm{av}}$ should be less than $\varepsilon_{\mathrm{c}}$ for localization (20). In figure 23, the computed values of $\varepsilon_{\mathrm{tr}}$ (using (15)) and the experimental values of $\varepsilon_{\mathrm{c}}$ (from Tirupataiah and Sundararajan 1991a) are indicated in the form of bar graphs for a number of metallic materials. 


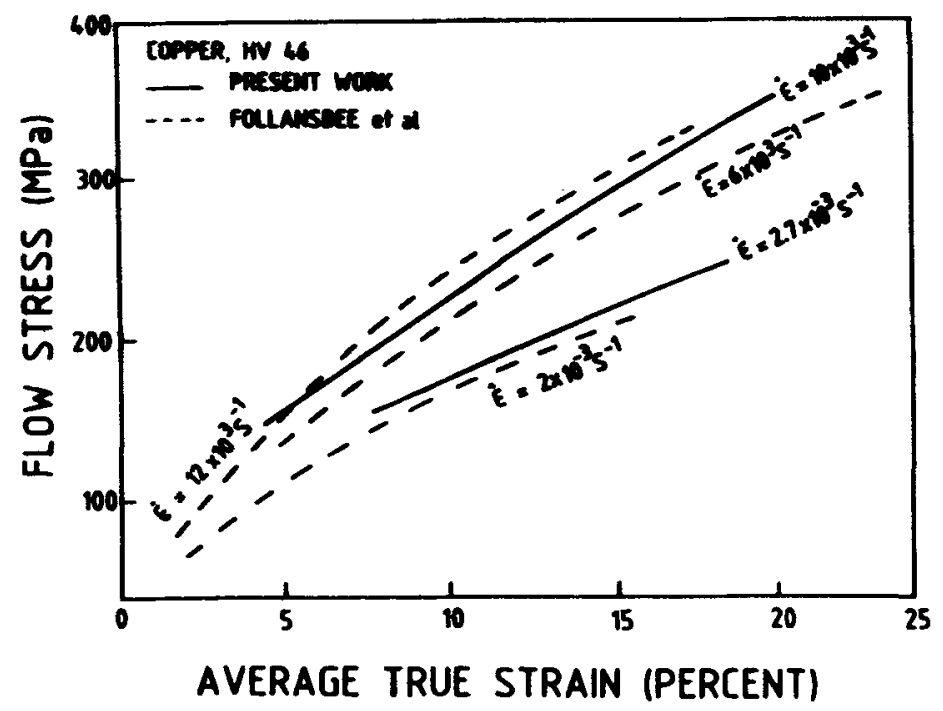

Figure 21. A comparison of the present dynamic and static data (full lines) for copper with that of Fullinsbee et al idotted lines).

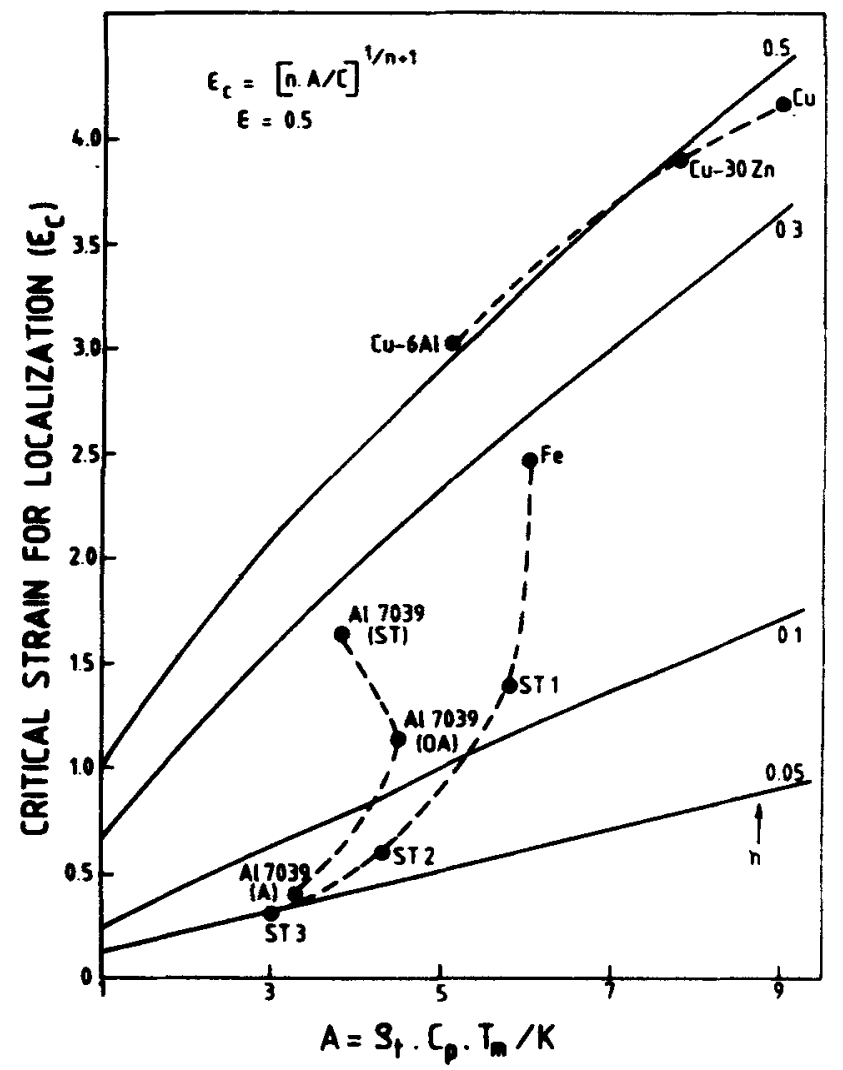

Figure 22. The variation of $\varepsilon_{c}$ predicted by $(20)$ as a function of parankicr $A$ for a number of test matcrials. 


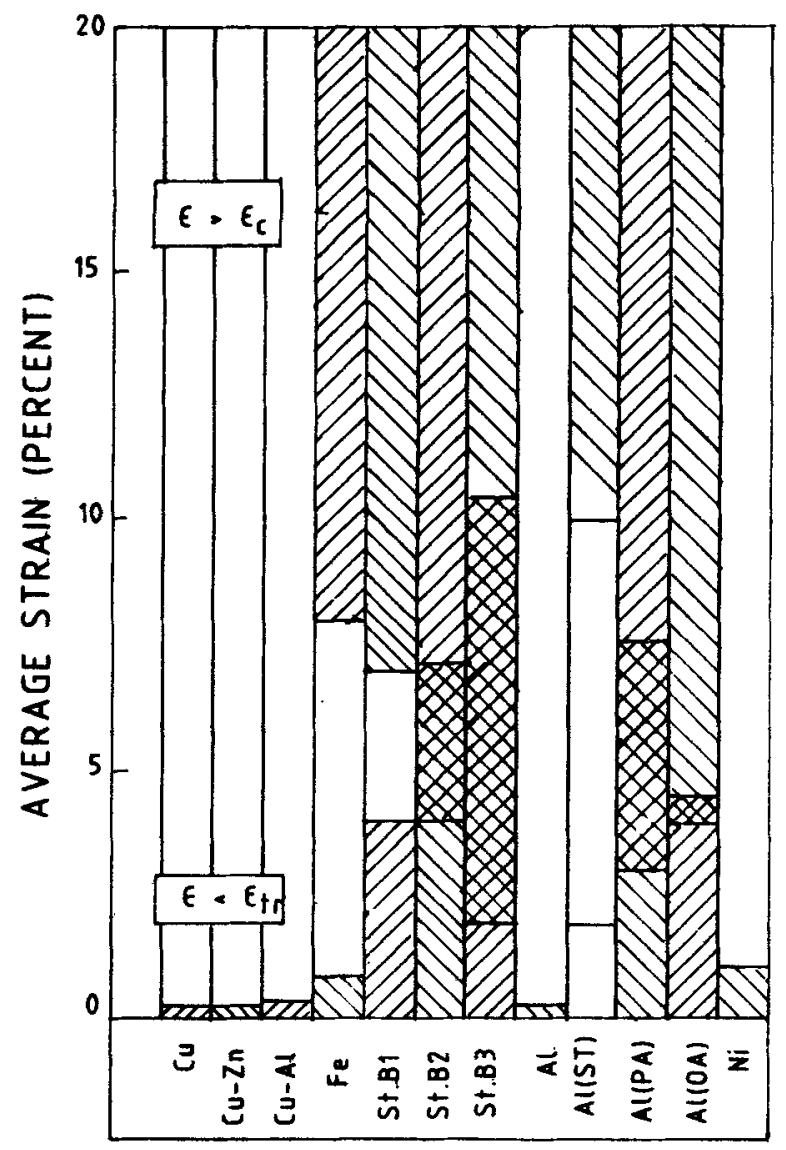

Figure 23. The computed values of $\varepsilon_{t r}(9)$ and the experimental values for $\varepsilon_{\boldsymbol{c}}$ for a number of mutals and alloys. Each bar in the figure represents one material.

If static indentation conditions are considered, $\varepsilon_{\mathrm{av}}$ should exceed $\varepsilon_{\mathrm{tr}}$ for obtaining a strain independent $C$. From figure 23 , it is clear that $\varepsilon_{\mathrm{tr}}$ varies quite widely depending on the test material properties. The value of $\varepsilon_{\mathrm{tr}}$ is lower than $1 \%$ in the case of metals and alloys like $\mathrm{Cu}, \mathrm{Cu}-\mathrm{Zn}, \mathrm{Cu}-\mathrm{Al}, \mathrm{Fe}, \mathrm{Al}$ and $\mathrm{Ni}$. In contrast, in the case of steels and $\mathrm{Al}$ alloy in the peak and overaged conditions, $\varepsilon_{\mathrm{tr}}$ exceeds $4 \%$ and becomes as high as $10.6 \%$ in steel with a hardness of $\mathrm{Hv} 571$.

A strain independent value for $C$ is possible under dynamic conditions only if $\varepsilon_{\mathrm{av}}<\varepsilon_{\mathrm{c}}$ in addition to the other condition $\varepsilon_{\mathrm{av}}>\varepsilon_{\mathrm{tr}}$. In figure 23, the experimental values of $\varepsilon_{c}$ are also indicated except for cases where $\varepsilon_{c}$ exceeds $20 \%$. Strains beyond $20 \%$ are not considered since the indentation technique is not capable of inducing average strains in excess of $20 \%$. Thus, for each material represented as a bar in figure 23 , the portion of the bar which remains unshaded represents the useful $\varepsilon_{\mathrm{av}}$ regime wherein a strain-independent $C$ value can be obtained under dynamic indentation conditions. A perusal of figure 23 , with the above definition in mind, indicates that the useful $\varepsilon_{\mathrm{av}}$ regime is large for materials like $\mathrm{Cu}, \mathrm{Cu}-\mathrm{Zn}$, $\mathrm{Cu}-\mathrm{Al}, \mathrm{Al}$ and $\mathrm{Ni}$. In the case of materials like $\mathrm{Fe}$, steel $\mathrm{Bl}(\mathrm{Hv} 260$ ) and $\mathrm{Al}$ alloy (ST condition), the useful $\varepsilon_{\mathrm{av}}$ regime is quite restricted (e.g. between 1 and $8 \%$ 
for iron and between 4 and $7 \%$ for steel B1). Finally, in the case of steels B2 ( $\mathrm{Hv} 425)$ and $\mathrm{B} 3$ ( $\mathrm{Hv}$ 571) and $\mathrm{Al}$ alloy in peak aged and overaged conditions, an useful $\varepsilon_{\mathrm{av}}$ regime does not exist under dynamic indentation conditions. Thus, for such alloys, the hardness test should not be utilized to derive the flow stress-strain relationship.

\section{Conclusions}

In this paper, the correlation that exists between hardness and flow stress in metallic materials, has been examined in detail. The experimental procedure for deriving flow stress-strain relationship from static or dynamic hardness tests using the constraint factor approach has been described. In particular, the indentation test conditions required for obtaining a strain independent constraint factor has been analyzed for both static and dynamic indentation conditions. In addition, it has been demonstrated that even under test conditions wherein $C$ is independent of strain, the test material parameters (like $K$ and $n$ ) does influence the magnitude of $C$. An empirical relation which accounts adequately for the influence of material properties on $C$, has been proposed.

\section{References}

Follansbee P S and Kocks U F 1988 Acta Metall. 3681

Francis H A 1976 J. Eng. Mater. Technol. Trans. ASME 98272

Johnson K L 1985 Contact mechanics (UK: Cambridge University Press) Chapter 6

Matthews J R 1980 Acta Metall. 28311

O'Neill H 1967 The hardness of metals and alloys (London: Chapman and Hall)

Sundararajan G and Shewmon P G 1983 Actu Metall. 31101

Tabor D 1951 The hardness of metals (Oxford, UK: Clarendon Press)

Tirupataiah Y and Sundararajan G 1987 Mater. Sci. Engg. 91169

Tirupataiah $Y$ and Sundararajan G 1990 Int. J. Impact Engg. 9237

Tirupataiah Y, Venkataraman B and Sundararajan G 1990 Mater. Sci. Engg. A124 133

Tirupataiah Y and Sundararajan G 1991 a J. Mech. Phys. Solids 39243

Tirupataiah $Y$ and Sundararajan G 199/b Metall. Trans. A22 2375 